\title{
Production of Syngas from Biomass Using a Downdraft Gasifier
}

\author{
Hassan Golpour, $\mathrm{PhD}^{1}$, Teja Boravelli ${ }^{2}$, Joseph D. Smith, $\mathrm{PhD}^{3}$, \\ Hamid R. Safarpour ${ }^{4}$ \\ ${ }^{I}$ Department of Chemical and Biomolecular Engineering, North Carolina State University, Raleigh, NC, USA \\ ${ }^{2}$ Departments of Chemical and Biochemical Engineering, Missouri University of Science and Technology, \\ Rolla, MO, USA \\ ${ }^{3}$ Departments of Chemical and Biochemical Engineering, Missouri University of Science and Technology, \\ Rolla, MO, USA \\ ${ }^{4}$ Department of System Engineering, Missouri University of Science and Technology, Rolla, MO, USA
}

\begin{abstract}
The role of biomass in energy and fuel production as an alternative to fossil fuel is vitally important considering carbon dioxide production vs. secure energy. Sustainable, renewable and reliable resources of domestically produced biomass together with wind and solar energy are sensible options to support a small-scale power generation to meet local electricity demand plus provide heat for rural development. The present work focuses on:

1. Design, build and operate a vertical downdraft biomass gasifier with tar removal

2. Establishing the optimum operating methodology and parameters to maximize syngas production in biomass gasification through process testing.

The one ton per day biomass gasification process unit designed in this work included a downdraft biomass thermochemical conversion gasifier, gas transportation line with tar removal and an enclosed combustion chamber. The reactor used internal heat transfer surfaces to enhance intra-bed heat and mass transfer inside the reactor. Three different woody biomass feedstock including pellets, picks and flakes were examined in this work. Specific results described in this paper include identifying and characterizing the key operating factors (i.e., temperature profile, feed stock carbon/hydrogen mass ratio, and air flow rate) required to optimize reactor yield. To achieve the maximum syngas production yield, experiments carried out using classical experimental design methodology.
\end{abstract}

Keyword: biomass to fuel, downdraft gasifier, gasification, renewable energy, synthetic gas, thermochemical conversion

\section{INTRODUCTION AND BACKGROUND}

Energy is the major facilitator of the modern life. Every developed and developing economy requires access to advanced sources of reliable energy to support its growth and prosperity. Nowadays, the present energy services have enhanced the living in innumerable ways resulting an inseparable relation between global population and energy production. The relation between world population and its demand on energy is shown Fig 1 [1].However, easily accebile energy supplies to meetsociety demand has become challenging recently due to societies enormous consumption. Fossil fuels continues to be the primary source of energy with coal, oil and natural gas contribution to around $87 \%$ of global energy demands [2]. Fossil fuels are generally considered non-renewable source of energy as they cannot be easily re-generated in areasonable time to be sustainable. The depletion of fossil fuels compelssociety to explore alternative energy sources to meet future world energy demands [3].

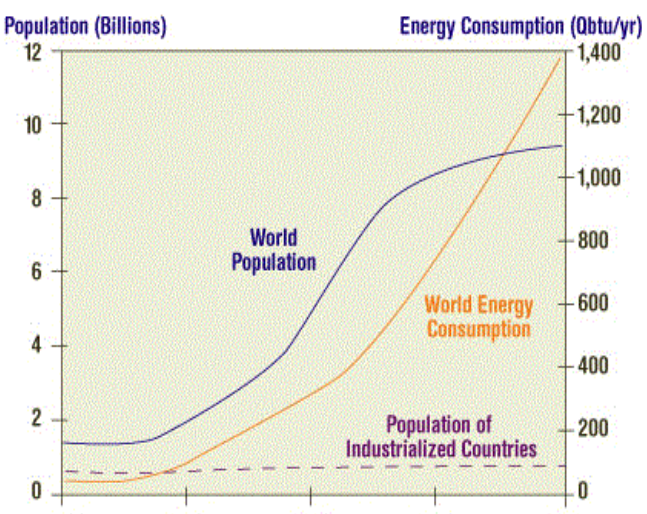

Figure 1-World population vs. energy demand

The transition from non-renewable energy resources to renewable energy resources is increasing, as the number of alternative renewable energy choices expand to solar, wind, biomass and geothermal energy. Recent studies show a 6\% increase in renewable energy use to supply society energy during the past two decades from late 90's to 2020 [4]. Apart from their depletion, fossil fuels 
combustion release greenhouse gases $\left(\mathrm{H}_{2} \mathrm{O}, \mathrm{CO}_{2}\right)$ and noxious emissions $\left(\mathrm{NO}_{\mathrm{X}}, \mathrm{CO}\right)$ that have a severe impact on the environment. In United States, about $90 \%$ of the greenhouse gases are due to combustion of fossil fuels [5]. Biomass as a renewable energy source, can serve to augment or replace for fossil fuel to meet the increasing energy demand. In 2010, renewable energy accounted for $16.7 \%$ of the world energy supply with biomass contributing about $70 \%$ (Fig 2) [6].

\subsection{Biomass Gasification}

Biomass is defined as organic matter derived from dead or living organisms mainly composed of carbon, hydrogen, oxygen, nitrogen and small amount of sulfur and some heavy metals. As an energy source, biomass can either be used directly via combustion to produce heat, or indirectly after conversion to various forms of biofuel. Three common types of biomass are woody biomass, nonwoody biomass and animal or mankind. Among all of these, wood is the largest sustainable source of biomass energy [7]. Wood is a viable option for replacement or augmentation of coal in industrial combustors and gasifiers. To reduce carbon emissions, variation of fuels is not the only option. Other options include different conversion process (i.e. digestion) and variation in conversion technologies (i.e. gasifier). Among the technologies available to produce energy from biomass, gasification is relatively efficient method which is generally environmentally benign. Gasification represents a thermo-chemical conversion process that convert carbonaceous material at elevated temperatures to syngas. In general, the production of heat and/or power with comparatively high efficiency is possible using low BTU feedstocks such as biomass, refinery residues or municipal wastes. This process involves carbonaceous material at high temperatures with a controlled amount of air (oxygen) or steam. Biomass gasification process typically consists of four main steps: drying, pyrolysis, combustion and reduction. These steps include both exothermic and endothermic chemical reactions to produce the final syngas product. During this process, steady operating involves the gasifier maintaining a certain temperature profile [8]. Since it produces no net increase in greenhouse gas (GHG) emissions on a life-cycle basis (or absorbs the amount of carbon dioxide emitted during the powerproduction cycle), biomass gasification is considered a carbon neutral process with environmental advantages over conventional energy production [9]. The main product of biomass gasification is commonly referred to as synthetic gas (syngas) which is a mixture of $\mathrm{CO}, \mathrm{CO}_{2}, \mathrm{CH}_{4}$ and $\mathrm{H}_{2}$.

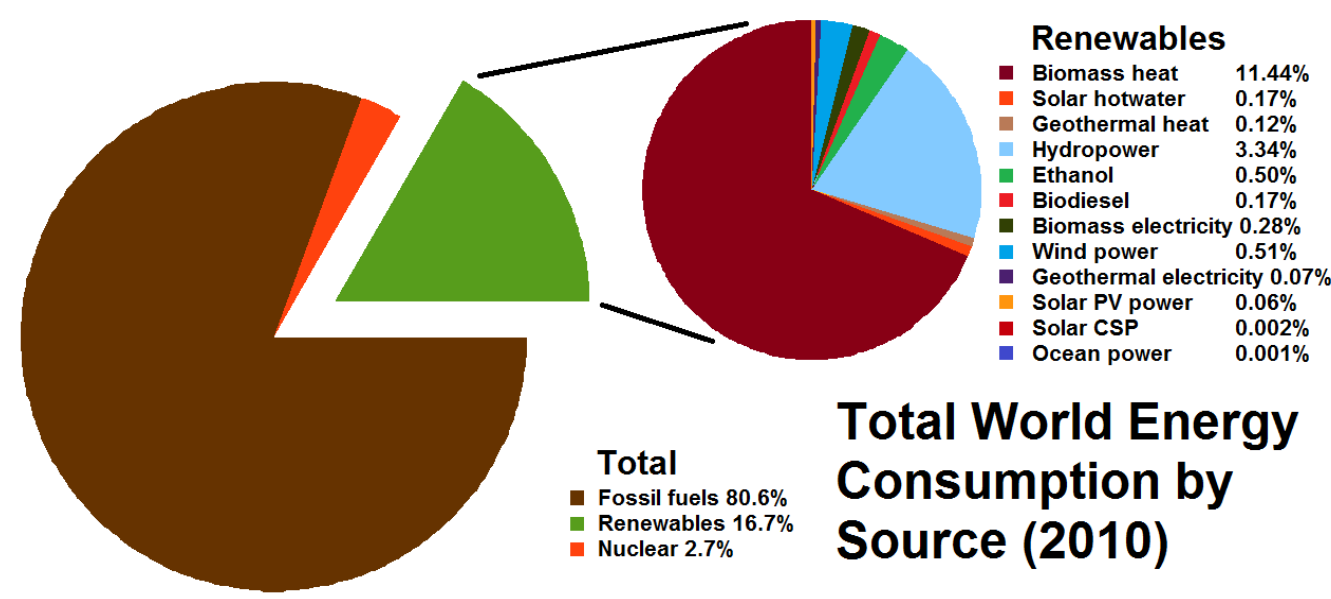

\subsection{Types of Gasifiers}

Biomass gasifiers can be generally classified into two broad categories: fixed bed and fluidized bed. Various types of gasifier designs are briefly explained below [10]. Fixed Bed Gasifier (updraft and downdraft): the fixed bed is composed of carbonaceous material and is classified by the flow of gasifying agent (air/steam) through the gasifier [11]. Updraft Gasifier-simple, low cost design where biomass enters from the top while air is entering from the bottom. They are also known as counter flow gasification, as shown in Fig 3 [12]. Hot syngas produced in the gasifier passes up through the pyrolysis and drying zones to heat raw feedstock. Internal heat exchange between hot syngas and cooler biomass feed produces low temperature syngas. The main disadvantage of updraft gasifiers is that they produce high amount of tar which needs to be separated from syngas [13].

Downdraft Gasifier-Air moves concurrently with the biomass feed entering from the upper part of the gasifier. As shown in Fig 3, the grate supports the fixed bed, where reduction occur followed by combustion, pyrolysis and drying zone on the top respectively. The tar produced in the pyrolysis zone passes through the combustion zone where it is 
cracked to produce more tar free syngas. This represents the main advantage of this method. The main disadvantage is using low density feedstock which causes transportability or flow problems and excessive pressure drop through the system and is discussed in more detail later [14,15].

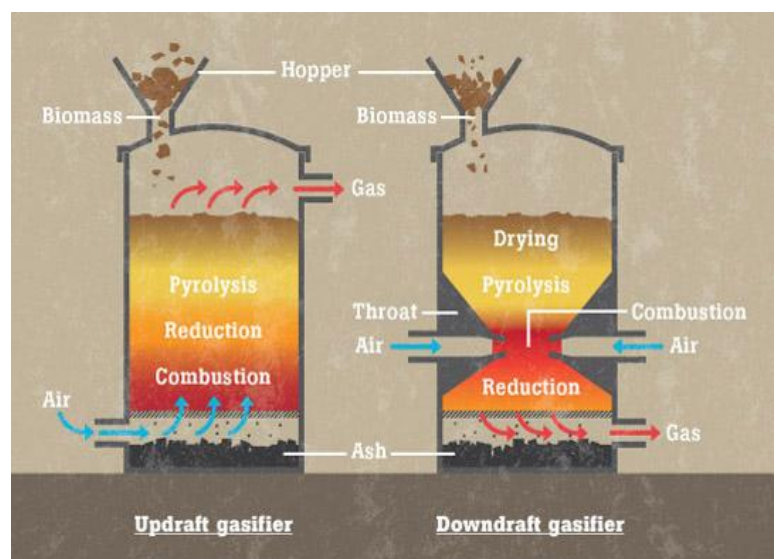

Figure 3 -Updraft and downdraft gasifiers

Fluidized Bed Gasifier (bubbling bed, circulating fluidized bed): Feedstock particles are fed from reactor side to a preheated granular (sand) bed, where the air or steam is fed through the bottom to fluidize biomass particles in the gasifier $[11,16]$ as shown in Fig 4 [17].The upward drag force of gas thoroughly mixes the suspended solid particles inside the gasifier with the air, thereby increasing the solid fluid interactions compared to updraft or downdraft gasifiers. The major advantage of fluidized bed gasifiers is the uniform temperature profile in the gasification zone created by circulating fluid through fine granular material. Loss of fluidization due to plugging the bed is the major disadvantages of fluidized bed gasifier [15].

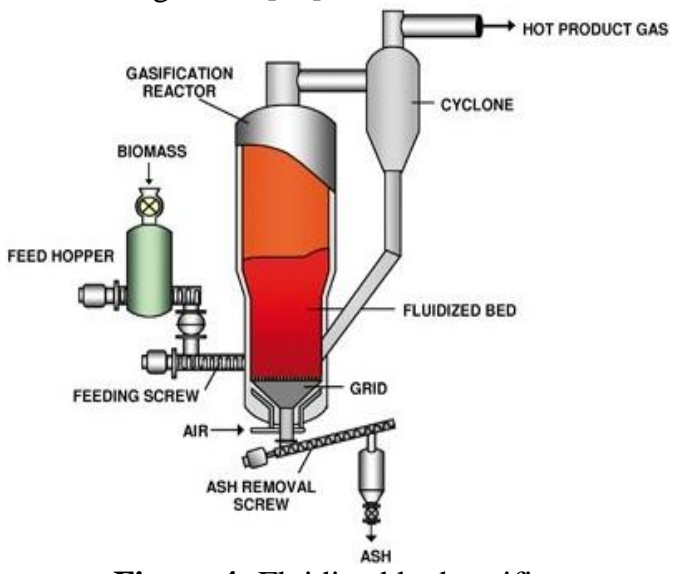

Figure 4 -Fluidized bed gasifier

\subsection{Processing Zones in a Downdraft Gasifier}

Drying Zone - is located at top entrance of the gasifier. The main process occurring in this zone is fundamentally dehydration or removal of moisture content of the feed while no decomposition or chemical reaction occurs. Biomass feedstock normally has moisture content of 5 to $55 \%$. The dehydration process occurs at the temperature 150 $250^{\circ} \mathrm{F}$. The heat required for dehydration is transferred mainly by conduction from the lower zones in the gasifier.

Pyrolysis Zone-pyrolysis or devolatilization of the feedstock involves thermal decomposition in the absence of oxygen. The irreversible devolatilization reactions take place in this zone at temperature between $400^{\circ} \mathrm{F}$ to $900^{\circ} \mathrm{F}$ [18]. Energy required for pyrolysis is supplied from combustion zone where the exothermic reactions occur. Devolatilization products include volatile, char and tar which accounts for approximately $85 \%$ of feedstock. The volatile component consists of mixture of $\mathrm{H}_{2}, \mathrm{CO}, \mathrm{CH}_{4}, \mathrm{H}_{2} \mathrm{O}$, and $\mathrm{CO}_{2}$ along with heavy hydrocarbon which condense into a black corrosive liquid tar. Char is the solid carbon residue. The tar and char will further undergo decomposition partial reduction in the combustion and gasification zones. Pyrolysis and tar cracking reactions occur to form primary tar (expressed as $\mathrm{C}_{6 \cdot 407} \mathrm{H}_{11.454} \mathrm{O}_{3.482}$ ) and secondary tar (assumed as benzene) [19].

Volatile $\rightarrow 0.268 \mathrm{CO}+0.295 \mathrm{CO}_{2}+0.094 \mathrm{CH}_{4}+$ $0.5 \mathrm{H}_{2}+0.255 \mathrm{H}_{2} \mathrm{O}+0.004 \mathrm{NH}_{3}+0.2$ primary tar (1) Primary tar $\rightarrow 0.261$ secondary tar $+2.6 \mathrm{CO}+$ $0.441 \mathrm{CO}_{2}+0.983 \mathrm{CH}_{4}+2.161 \mathrm{H}_{2}+0.408 \mathrm{C}_{2} \mathrm{H}_{4}$ Oxidation/Combustion Zone: supplies the energy for the subsequent gasification and pyrolysis reactions. All the oxidation reactions are exothermic in nature and yield the temperature ranging from $1400^{\circ} \mathrm{F}$ to $2100^{\circ} \mathrm{F}$. The carbon content of volatiles and chars reacts with oxygen to form carbon dioxide whereas, hydrogen and methane react with oxygen to produce steam or water vapor and carbon monoxide [19].

$\mathrm{C}+\mathrm{O}_{2} \rightarrow \mathrm{CO}_{2}$

$\mathrm{H}_{2}+1 / 2 \mathrm{O}_{2} \rightarrow \mathrm{H}_{2} \mathrm{O}$

$\mathrm{CH}_{4}+1.5 \mathrm{O}_{2} \rightarrow \mathrm{CO}+2 \mathrm{H}_{2} \mathrm{O}$

Reduction/Gasification Zone: in this zone, a number of high temperature chemical reactions between different gaseous and solid reactants take place in the absence of oxygen in a temperature range of $1100^{\circ} \mathrm{F}$ and $1700^{\circ} \mathrm{F}$. In general, the produced carbon dioxide, water vapor, partially combusted volatiles, and chars from above zones pass through the porous red hot charcoal bed resting above the grate to undergo reduction. The major reactions taking place in this zone are water gas reaction and the Boudouard reaction. The reduction reactions in this zone are mentioned below $[15,20]$ :

Water gas reaction

$\mathrm{C}+\mathrm{H}_{2} \mathrm{O} \rightarrow \mathrm{CO}+\mathrm{H}_{2}$

Water shift reaction

$\mathrm{CO}+\mathrm{H}_{2} \mathrm{O} \rightarrow \mathrm{CO}_{2}+\mathrm{H}_{2}$

Boudouard reaction

$\mathrm{C}+\mathrm{CO}_{2} \rightarrow 2 \mathrm{CO}$

Methanation reaction

$\mathrm{C}+2 \mathrm{H}_{2} \rightarrow \mathrm{CH}_{4}$

$$
\begin{array}{r}
\Delta H=+118.5 \mathrm{KJ} / \mathrm{mol} \\
(7) \\
\Delta H=-40.9 \mathrm{KJ} / \mathrm{mol}
\end{array}
$$

$\Delta H=+159.9 \mathrm{KJ} / \mathrm{mol}$
$\Delta H=-87.5 \mathrm{KJ} / \mathrm{mol}$ 


\subsection{Applications of Gasification}

Main applications of syngas are in Fischer Tropsch process, bio-diesel production, electricity mixture of carbon monoxide and hydrogen into liquid hydrocarbons, simply producing clean biofuels from synthesis gas. Of all the major applications of gasification, the electricity generation and Fischer Tropsch process contributes to nearly about $50 \%$. According to the US department of energy, in 2009, the potential of biomass usage in electricity generation is projected to be $22 \mathrm{GW}$ by the year 2022 [22].

\section{DESIGN AND FABRICATION}

The design and fabrication of the down draft biomass gasifier to produce syngas, is the main objective of this paper. The design is divided into three sections namely, fixed bed reactor, transfer line and the combustion chamber. The reactor, transfer line and combustion chamber were fabricated from carbon steel and black iron (see Fig 5).

\subsection{Reactor}

The down-draft fixed bed reactor consists of two concentric cylinders called reactor core (inner) and syngas plenum (outer) described below.

Reactor Core- The reactor core is the inner cylinder made of carbon steel with an internal diameter of 8in and a height of 19in. A wire mesh is attached via a chain to the bottom of this cylinder to support the biomass bed and also allow ash to exit the bed continuously. A visual image of inside the reactor core was possible via a HD camera connected to process control computer, is place on the stand $4 \mathrm{ft}$ above the top opening of reactor shown in Fig 6.Syngas Plenum -A space between the inner and outer cylinders is called syngas plenum which was sealed with a donut shaped metal plate. The outer cylinder was 20in diameter and 36in length. An induced draft (ID) fan was installed between gasifier and the combustion chamber to draw air into the generation, production of ammonia, methanol, hydrogen and etc. [21]. The Fischer Tropsch is a collection of chemical reactions that converts a gasifier and transfer the produced syngas from the reactor core to syngas outlet. Ash collected from the biomass bed was removed through a valve at the bottom of the syngas plenum. Gasifier effluent flowing from the syngas plenum enters the transfer line which included "tar-collection" devices. A hopper mounted at the top of the reactor supplied a continuous feed to the gasifier. The reactor also had a small inlet to purge nitrogen during the shutdown process to extinguish ongoing reactions. The thermal profiles of the reactor were monitored using Lab VIEW with three thermocouples placed inside each zone in the reactor, Fig 7. These three thermocouples were inserted at the height of 2", 7.5" and 13" from the reactor bottom which provided the temperatures from each zones. The top thermocouple measured the drying zone temperature around $150-250^{\circ} \mathrm{F}$ followed by combustion and gasification zones with average temperature of around $1800^{\circ} \mathrm{F}$ and $1500^{\circ} \mathrm{F}$ respectively measured by the middle and bottom thermocouples.

\subsection{Transfer Line/Tar Condensation System}

A U-shape transfer line connected to the syngas exit an ID fan was used to separate syngas from tar. The transfer line had two valves at the bottom of the "U" to collect the bio-oil (tar) produced. An upstream ball valve was installed in this section, to control the flow through the system, set at 0 when fully closed and 8 when fully open. For steady state operation valve was set between 2 and 3 to allow air into the gasifier. Velocity and flow rates according to the setting are shown in Table 1 . To collect samples of produced gas, a T-junction equipped with ball valve was placed after the ID fan. This valve was normally closed which allowed all syngas to be fed to the combustion chamber.

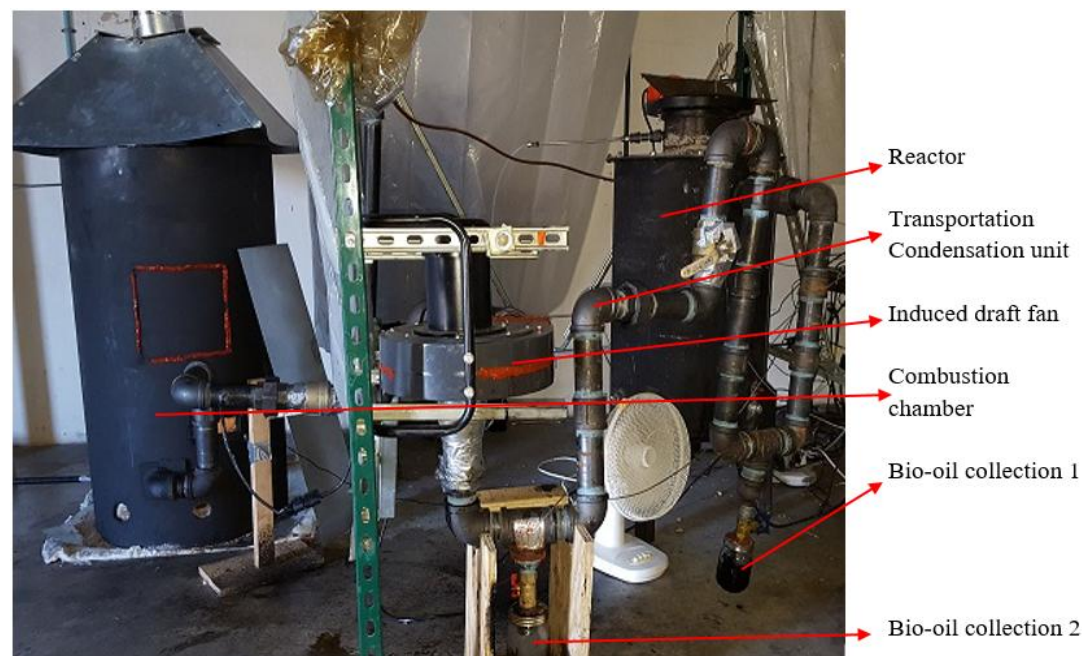

Figure 5 -Complete gasification process unit 
Three thermocouples were attached in the transfer line which were connected to the control system, provided the temperatures of the product gas coming from the gasifier (syngas out), going into the fan (fan in), and exiting the fan to the combustion chamber (fan out). Additionally, two oxygen sensors were placed in the transfer line, one after the syngas outlet and one before the combustion chamber. These sensors measure the concentration of oxygen in upstream and downstream gas to ensure no air leaks into the system. To avoid flaming the gas mixture, it is very important to maintain the oxygen concentration in the flowing gas always below $1 \%$ which results in a very rich mixture of syngas and oxygen. The upper and lower flammable limit of hydrogen $(75 \%$ - 4\%), carbon monoxide $(75 \%$ $12 \%)$, and methane $(15 \%-5 \%)$ confirmed that $1 \%$ oxygen by volume in the mixture allowed the safe operation. Oxygen sensors were always monitored and recorded for safety operation. The components in transfer line are shown in Fig5.

\subsection{Enclosed Combustion Chamber}

A carbon steel combustion chamber (enclosed flare) was 24in diameterby44in high. A final condensation section was connected to the feed to the chamber via a 2 in opening near the bottom of the chamber. 8 holes were included around the bottom of the chamber allow air to be drawn into the chamber to burn the syngas (Fig 8). A round gas (propane or natural gas) burner was placed at the bottom center of the chamber (Fig 9). Another HD camera was placed outside of chamber to monitor and record the flame through a window. Using glass fiber insulation, the inner chamber surface was insulated to avoid a hot external surface which would be a safety hazard and lead to mechanical failure. A thermocouple was placed at the top of the combustion chamber to monitor the exhaust gas temperature prior to the HVAC unit.

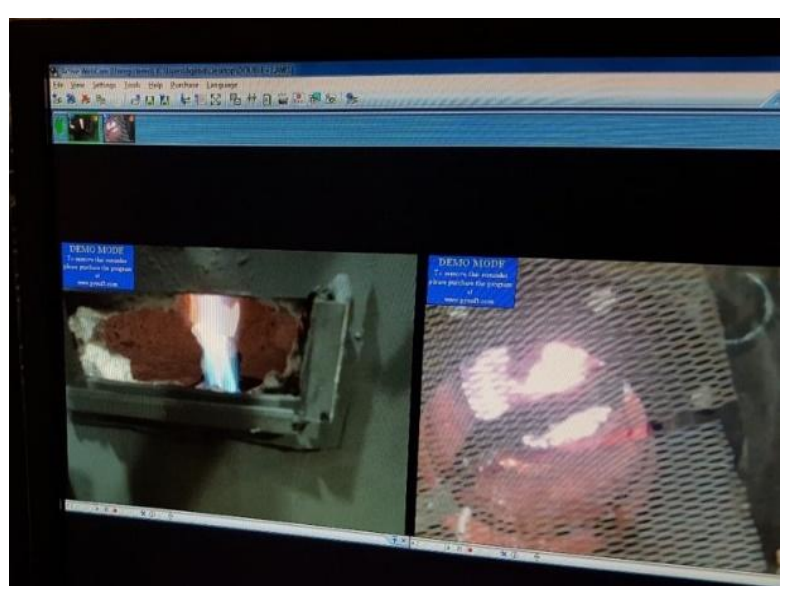

Figure 6 - Syngas flame and reactor core

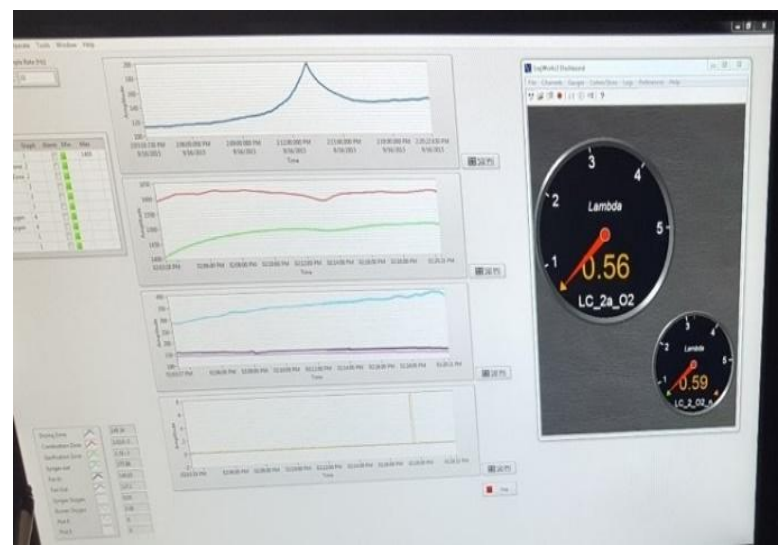

Figure 7 - Temperature profiles, oxygen concentrations

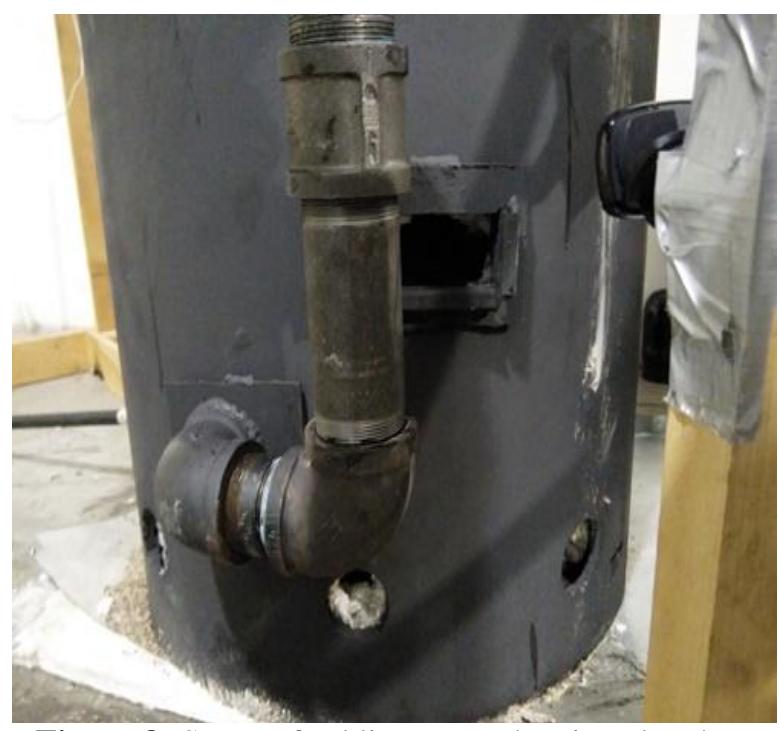

Figure 8 -Syngas feed line to combustion chamber

Table 1 -Velocity and flow of gas at different valve

\begin{tabular}{|l|c|c|}
\hline Setting & $\begin{array}{c}\text { Veltocity } \\
(\mathrm{ft} / \mathrm{min})\end{array}$ & $\begin{array}{c}\text { Flow }^{2} \\
\left(\mathrm{ft}^{3} / \mathrm{min}\right)\end{array}$ \\
\hline Setting 8 & 3170 & 69.15 \\
\hline Setting 7 & 3130 & 68.28 \\
\hline Setting 6 & 2130 & 46.46 \\
\hline Setting 5 & 1580 & 34.46 \\
\hline Setting 4 & 1150 & 25.08 \\
\hline Setting 3 & 680 & 14.83 \\
\hline Setting 2 & 320 & 6.98 \\
\hline Setting 1 & 25 & 0.545 \\
\hline Setting 0 & 0 & 0 \\
\hline
\end{tabular}

${ }^{1}$ Measured by hot wire anemometer

${ }^{2}$ Determined by gas density, pipe diameter and measured velocity 


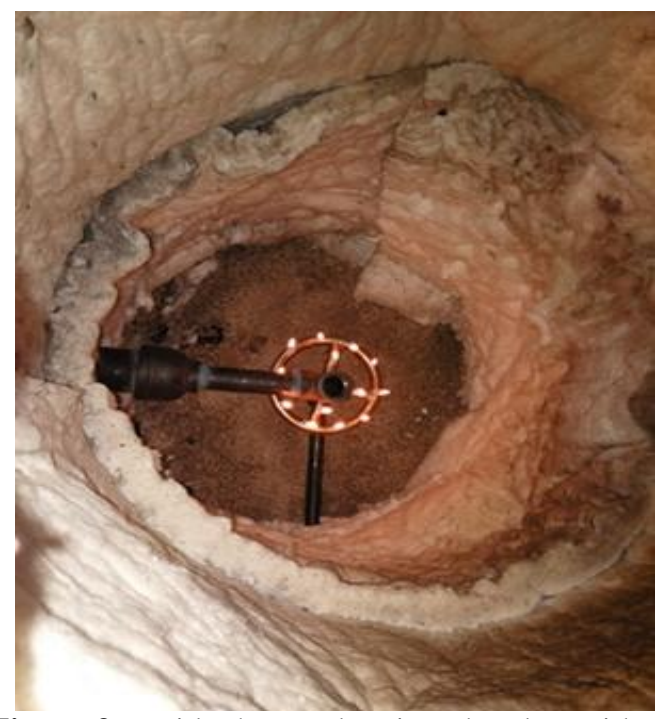

Figure 9 -Inside the combustion chamber with support fuel

\section{METHODOLOGY}

The feed properties and the experimental procedure used to run the gasifier are discussed below.

\subsection{Biomass Feedstock Characteristics}

Experiment were conducted considering three different feeds includingpellets, flakes and chips from oak and pine each with differentmoisture content, heating value and bulk density.As shown in Fig 10, the wood chipswereraw unprocessed high moisturematerial obtained from Canadian paper mill, and flakes and pellets werelow moisture processed material. Flakes were processed wood without bark and cut into small uniform sizes while pellets were made from compactedoak saw dust.Five samples of each type shown in Fig 8 were collected randomly and proximate and ultimate analyses for each were collected using a thermogravimetric analyzer and CHN elemental analyzer, respectively. These analyses were carried out on dry basis by placing samples in a vacuum oven for nearly eight hours at a temperature of $300^{\circ} \mathrm{F}$. The average proximate analysis, ultimate analysis and heating value of these feeds are shown in Table 2, Table 3and Table 4 respectively.

Table 2 - Proximate analysis

\begin{tabular}{|l|c|c|c|}
\hline Component & Chips & Flakes & Pellets \\
\hline Moisture \% & 35.19 & 11.01 & 7.56 \\
\hline Volatile dry \% & 82.28 & 86.15 & 87.23 \\
\hline $\begin{array}{l}\text { Fixed Carbon } \\
\text { dry \% }\end{array}$ & 17.26 & 13.32 & 12.39 \\
\hline Ash dry \% & 0.46 & 0.53 & 0.38 \\
\hline
\end{tabular}

Table 3 - Ultimate analysis

\begin{tabular}{|l|c|c|c|}
\hline Element \% & Chips & Flakes & Pellets \\
\hline Carbon & 48.81 & 48.24 & 49.03 \\
\hline Hydrogen & 5.96 & 6.15 & 5.58 \\
\hline Oxygen & 44.98 & 45.55 & 45.33 \\
\hline Nitrogen & 0.26 & 0.06 & 0.06 \\
\hline
\end{tabular}

Table 4 - Heating value

\begin{tabular}{|l|c|c|c|}
\hline Heating value & Chips & Flakes & Pellets \\
\hline $\mathrm{Cal} / \mathrm{gr}$ & 4509.90 & 4562.12 & 4621.76 \\
\hline $\mathrm{Btu} / \mathrm{lb}$ & 8117.82 & 8211.82 & 8319.16 \\
\hline
\end{tabular}

\subsection{Experimental Method}

The test procedure followed in these test included these main steps: a) start up, b) steady state continuous operation and c) shut down. Before operating the system, a hazard and operability study (HAZOP), is discussed below.

\subsubsection{Hazard and Operability Study (HAZOP).}

The HAZOP representeda structured and systematic examination of a planned or existing process and operating procedure to identify and evaluate potential hazards that may represent risks to personnel and/or equipment, or prevent efficient operation [23]. The HAZOP conducted was a qualitative measure, which aimed to stimulate the imagination of participants to identify potential hazards and operability problems. In this study, the whole system was divided to separate nodes or subsystems including (1) the reactor core, (2) the syngas plenum, (3) the tar trap, (4) the ID fan, (5) the solid char removal, (6) the transfer line, (7) the sampling branch and (8) the enclosed combustion chamber. For each sub-system, the standard possible causes were discussed which could lead to a dangerous situations. The cause and consequence of each condition was investigated and recommended remedies were identified to control or avoid the hazardous condition. A copy of final HAZOP spreadsheet was prepared and signed by all operators and people represented from environmental health and safety who participated in HAZOP.

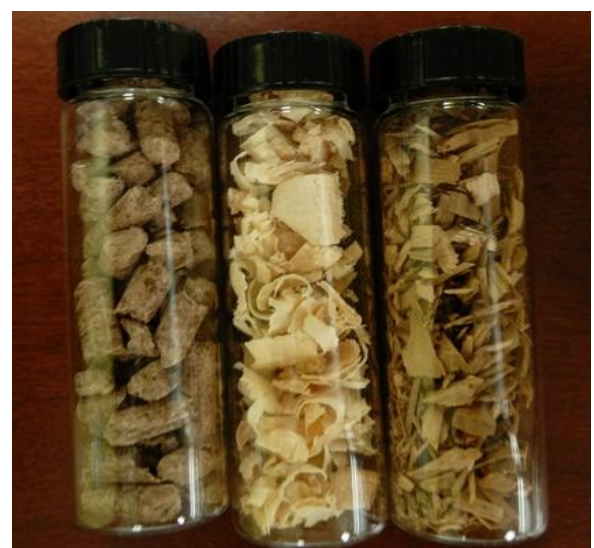

Figure 10 -Left to right: pellets, flakes and chips 
3.2.2 Start Up. Following the HAZOP, the following procedure was used to safely operate the gasifier. Combustion chamber was preheated by igniting the propane burner in the enclosed flare and starting the ID fan. Ten lb. of biomass was loaded into the reactor core and was ignited from the top. While the biomass was burning the upstream valve controlling air flow through the ID fan was set to 3 to pull the produced gas and smoke through the reactor and into the enclosed flare. As the reactions proceeded, the temperature increased to $1600-1800^{\circ} \mathrm{F}$ in combustion zone. Simultaneously both oxygen sensors showed approximately $0.6-0.8 \quad \mathrm{O}_{2} \%$. Remaining ash was removed from the bed through the ash grate. To enhance the flow, a vibrator attached to the inner cylinder was turned on to minimize bridging inside the reactor.

3.2.3 Steady State Operating Procedure. Approximately 4-8 $\mathrm{lb}$ of biomass feed (depending on feed type) was fed once the combustion zone was established. The temperature profiles of zones decreased following addition of the feed since it was at room temperature and had moisture. The temperatures increased again to steady state levels in combustion and gasification zones. During the steady state operation, the gasification zone (bottom of reactor) had a temperature of $1400^{\circ} \mathrm{F}$ while the combustion zone (located above the gasifier zone) had a temperature of $1600-1800^{\circ} \mathrm{F}$. By opening the air flow control valve, more air was fed into the reactor which resulted in increase in combustion and gasification zones temperatures. As the biomass were gasified through the reactor, new feed was added to the reactor and the above procedure was repeated for the steady state operation. Processing rates of biomass were between 0.5 to $1.5 \mathrm{lb}$ per minute depending on the type of the feed. To acquire the produced gas composition, samples were taken through the sampling branch located after the ID fan, before entering the combustion chamber. Taken samples were analyzed by a Gas Chromatography (GC) unit.

3.2.4 Shutdown. The ID fan was turned off and nitrogen was purged until the gasification reactions were extinguished. Then, the air flow control valve was closed and the top of the reactor was sealed, isolated the whole gasifier from the transfer line and combustion chamber which prevented air/gas from entering to or coming out from the reactor. Temperatures of the combustion and gasification zones decreased rapidly and then cooled down slowly for a full shutdown. It takes approximately 2 minutes to shut down the system and 3-5 hours for complete cool-down to room temperature. Finally, char remaining in the reactor was vacuumed out and tar collected was removed from the transfer line.

\section{RESULTS AND DISCUSSION}

Experiments were conducted for oak pellets, pine flakes and chips in the down draft biomass gasifier. The following section presents the results from these tests. The optimum operating conditions for the three feeds used in this experiments were found to be different given their composition and transportability.

\subsection{Pellets}

Fuel pellets made from compacted sawdust with a very low moisture content and high heating value were most transportable which avoided any bridging in the bed (compared to wood chips and flakes). Given the low moisture content, the pellets also ignited most easily and produced the highest syngas quality.

In addition to the air flow control valve, it was observed that the air flow into the reactor was affected by the amount of raw feed on the top of combustion bed. Depending on the feed type, the feeding rate should be optimized to get the proper air flow into the reactor. Too much air increases the temperature in combustion and gasification zones and results in pure combustion of the feedstock. On the other hand, lack of enough air stops the combustion reactions and consequently the gasification process. Temperature profiles inside the reactor core are shown in Fig 11.

As shown in Fig 11, the experiment was started at 11:51AM by igniting the pellets. The temperature in combustion and gasification zones were the key indicators to add a new pile of feed. Usually $1500^{\circ} \mathrm{F}$ for combustion and $1200^{\circ} \mathrm{F}$ for gasification are the good temperatures to start feeding the reactor. At 12:10PM, when the desired temperatures were achieved, a new pile of pellets was added to the reactor. The shutdown process was started at 2:43PM by turning the ID fan off, sealing the top opening of the reactor and purging nitrogen through the bed. Air flow control valve was kept open for less than a minute to let the nitrogen extinguish the reactions and sweep the whole system, and then closed to isolate the reactor. 


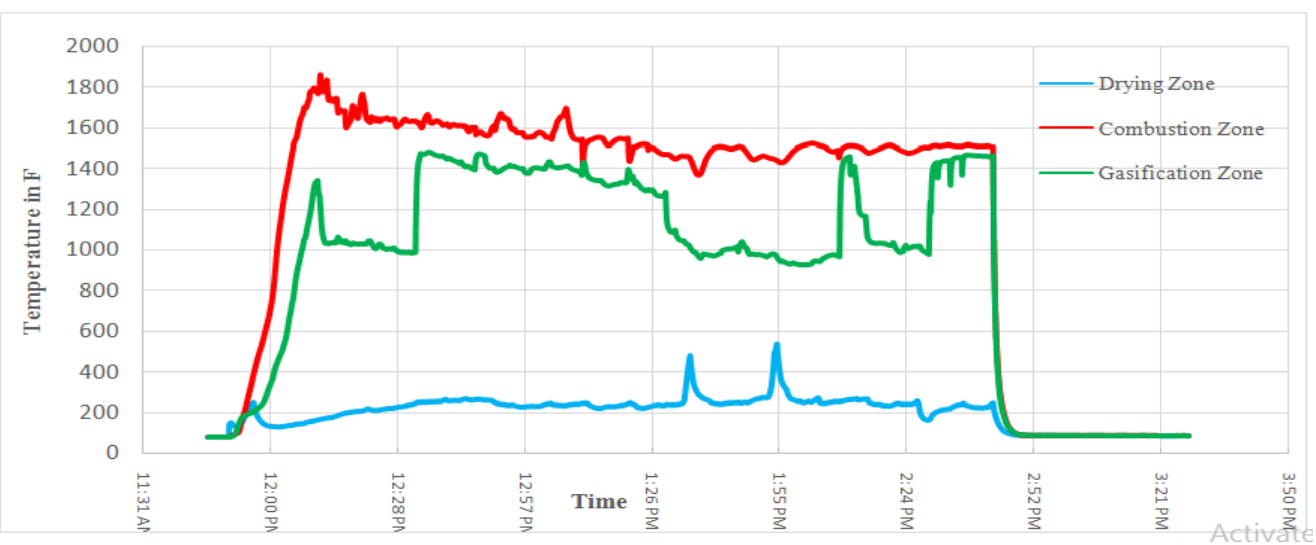

Figure 11 - Pellets temperature profiles inside the reactor core

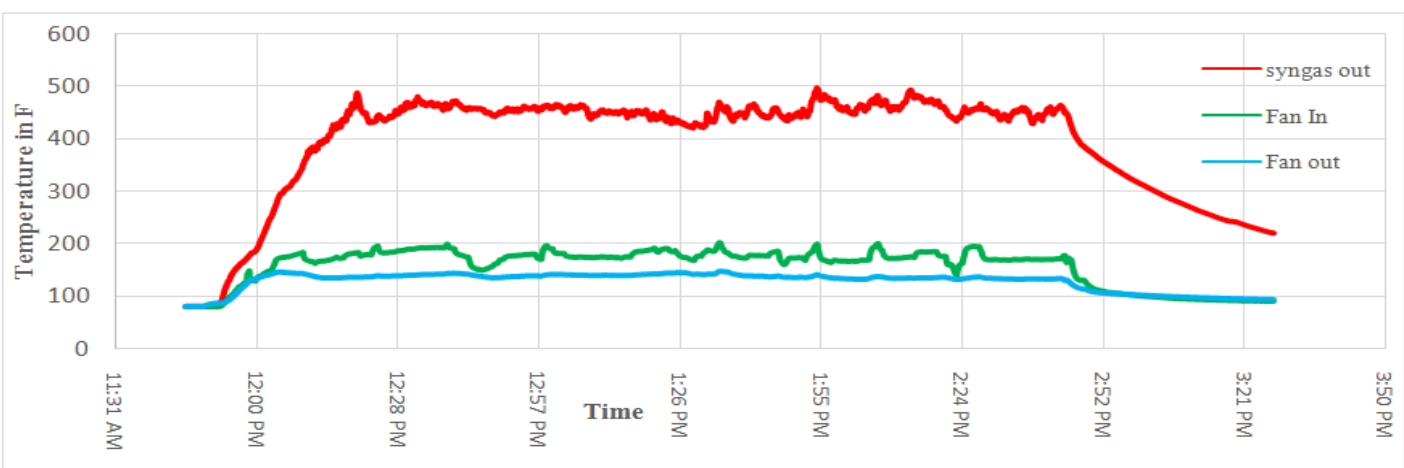

Figure 12 - Temperature profiles in the transportation unit for pellets

The temperature of syngas leaving the gasifier was directly related to the temperatures of gasification and combustion zones which were a function of air flow into the reactor. The produced syngas was cooled down (usually from $500^{\circ} \mathrm{F}$ to $200^{\circ} \mathrm{F}$ ) through the transfer line and bio-oil was collected through two outlets in the transfer line before the ID fan. The temperature of syngas coming out of the gasifier was always controlled $\left(<500^{\circ} \mathrm{F}\right)$ to avoid damaging the ID fan. Temperatures profiles of syngas outlet, fan inlet and fan outlet are shown in Fig 12.

\subsection{Flakes}

Like pellets, flakes (wood shavings) are also the processed materials with slightly higher moisture content. Flakes flowed much harder through the reactor compared to pellets. To assist the flow of flakes through the bed, a vibrator was attached to the inner cylinder of the reactor. Since flakes had much lower density than the other two feed stocks in this study, they were processed in a lower mass rate. This is not to be confused with the volumetric rate of processing of flakes which was much higher than pellets and picks, given its shape and void fraction in bulk. The temperature profiles inside the reactor and through the transportation are shown in Fig 13 and Fig14.

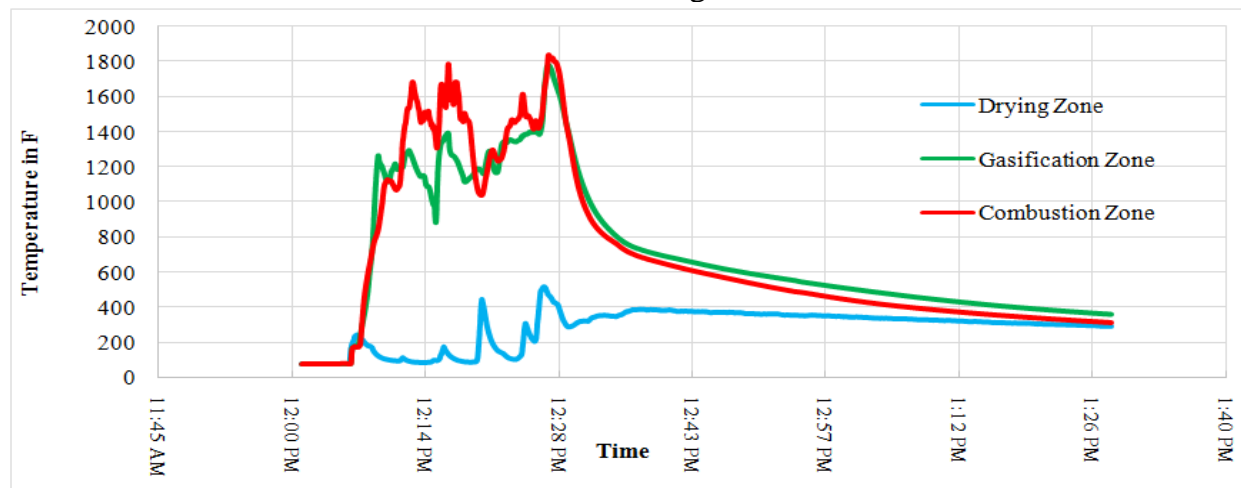

Figure 13 - Flakes temperature profiles inside the reactor core 


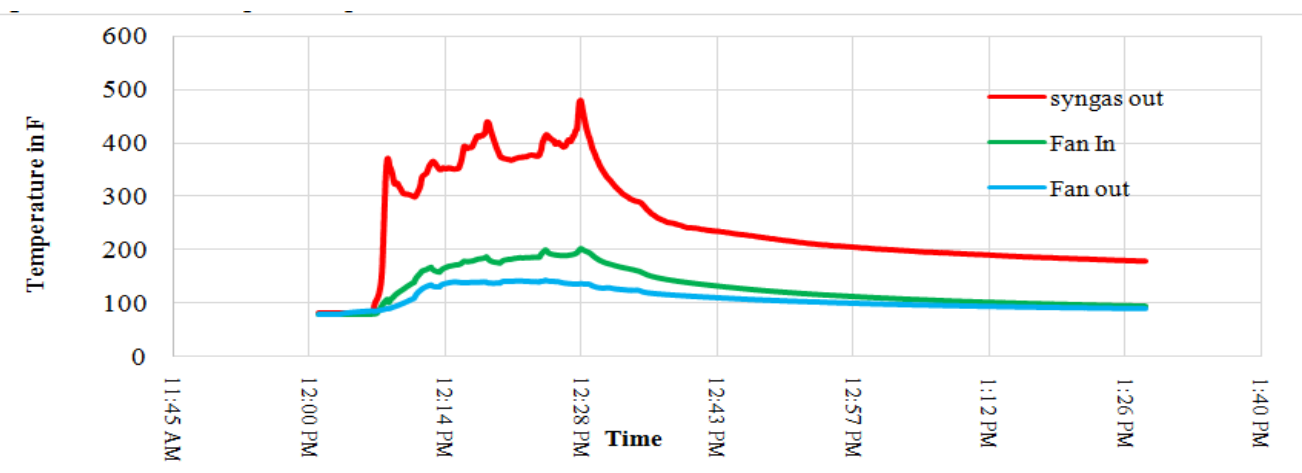

Figure 14 - Temperatures profiles in transportation unit for flakes

\subsection{Chips}

It was very difficult to start up the experiment using only chips, since they had 35\% moisture. So, there were two solutions for this problem: 1 . pre-dry the chips or 2 . mix them with pellets just for startup. In this experiment, option 2 was chosen since it was more economic and simple. Once a good combustion zone was achieved, then chips were added for steady state operation. Less than flakes and more than pellets, chips had a hard time to flow through the reactor. So, bridging and void creation were expected in the absence of vibrator. Since chips had the highest moisture content comparing to the other two feeds, it was recommended to run the gasifier at very low feed rate to avoid dramatic temperature drop in combustion and gasification zone sand maintain a stable combustion bed and steady state operation. The huge temperature drop at times 3:34 PM and 3:40 PM in Fig15occurred when large piles of chips were added to the system.

From the camera looking into combustion chamber, it was observed that the syngas flame from chips was less dense and stable compared to pellets. This indicated the low heating value of the produced syngas from wood chips with high moisture contents. Temperature profiles inside the reactor core and through the transfer line are shown in Fig 15and Fig 16.

\subsection{Syngas Composition and Bio-Oil/Tar Production}

The composition of syngas produced from pellets gasification process is shown in Table 5 . These values will vary if pure oxygen was used instead of air as gasification medium. From the result, $\mathrm{H}_{2}$ and $\mathrm{CO}$ as main components of interest shared about $40 \%$ of the total volume of the produced gas. On the other hand, a dark color liquid fuel, biooil/tar was formed as a side product of pyrolysis reaction. During the pyrolysis reaction, carbonaceous biomass feedstock underwent thermal degradation to form volatiles, char and ash. In case of low temperature and cold startup, these volatiles condensed and formed a brownish black thick liquid known as wood oil or bio-oil. Mainly it consists of $70 \%$ carbon, $7-9 \%$ hydrogen and $20 \%$ oxygen. It has significant amount of $20-30 \%$ miscible water depending on the moisture contents of biomass feedstock. The quality and composition of this bio-oil also rely on the type of pyrolysis and the composition of feedstock. Like biomass, bio-oil is also more environmental friendly fuel with less $\mathrm{CO}_{2}$ and $\mathrm{SO}_{2}$ emissions comparing to fossil fuels. It has a heating value of $25-30 \mathrm{MJ} / \mathrm{Kg}$ which is $25-35 \%$ lower compared to crude oil $[18,24]$.A picture of bio-oil that was collected during the startup process is shown in Fig 17.

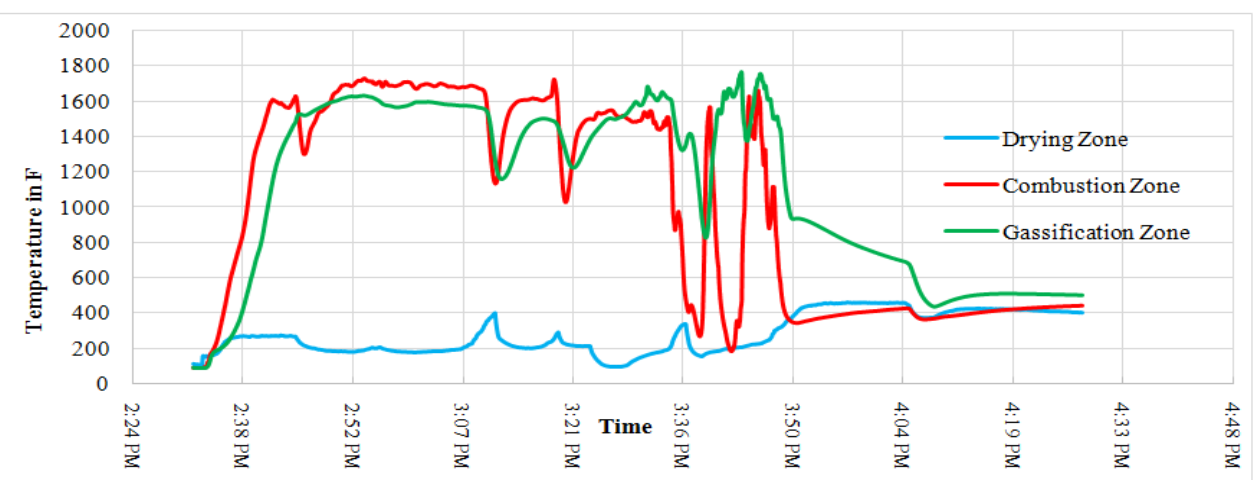

Figure 15 - Chips temperature profiles inside the reactor core 


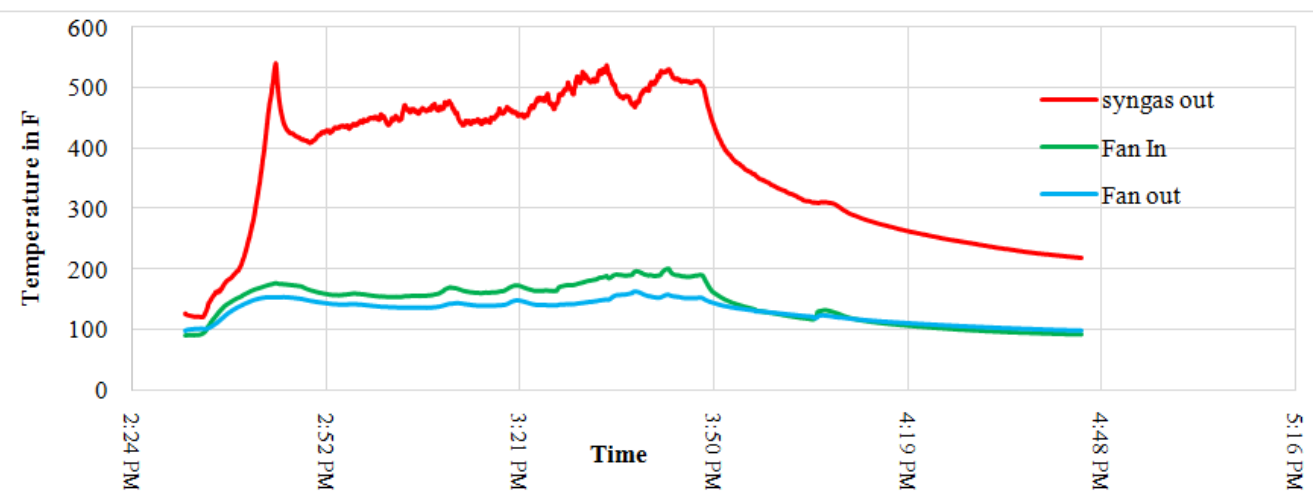

Figure 16 - temperature profiles in transportation unit for chips

Table 5 - Syngas composition

\begin{tabular}{|l|c|}
\hline Component & Volume \% \\
\hline Hydrogen & 18 \\
\hline Carbon monoxide & 21 \\
\hline Carbon dioxide & 16 \\
\hline Methane & 2 \\
\hline $\mathrm{C}_{2}^{+}$Hydrocarbons & 2 \\
\hline Nitrogen & 41 \\
\hline
\end{tabular}

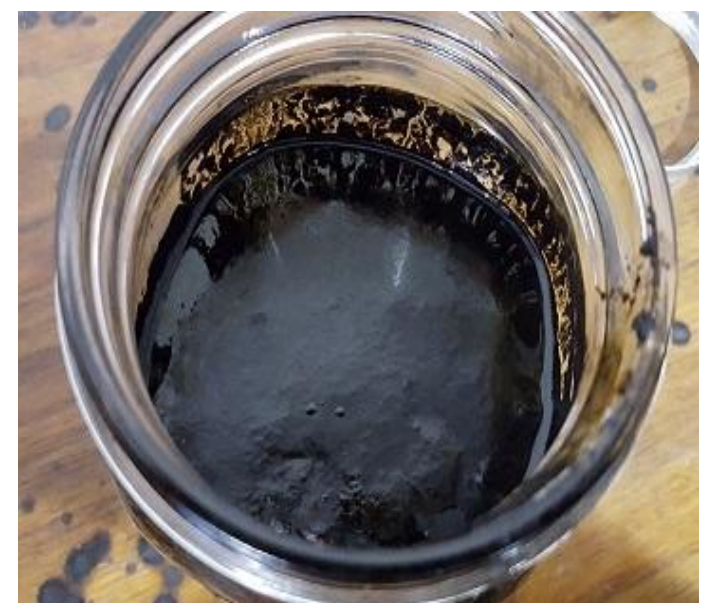

Figure 17 -Collected bio-oil during startup

\section{CONCLUSION AND ONGOING WORK}

A one ton per day downdraft biomass gasifier was designed, fabricated and operated to produce syngas, and various biomass feedstock including pellets, flakes and high moisture chips were successfully processed in the designed unit. All experiments were recorded and temperature profiles inside the reactor and through the transfer line were presented as well as syngas composition and bio-oil properties. Sensitivity analysis was performed to find out the effects of bed temperature, air flow rate and feed moisture content on the syngas production.

Biomass feed rate and air flow rate into the reactor played important roles to maintain steady state operation. So, an optimum level of feed rate and air flow rate were required to retain the steady state conditions. To maintain the process, higher air flow rate was required whenever feed rate was increased. It was also discussed that the feeds were different in terms of rate of combustion and gasification. Having higher density, higher heating value, lower moisture and cylindrical shape, pellets were transported easier through the reactor, maintained more stable combustion zone, and produced more stable and dense syngas flame comparing to chips and flakes. To study the effect of reactor size on the rate of production of syngas which is expected not to be linear, a scaling project is planned which includes changing the reactor core diameter down to 4in and up to 12 in instead of the existing 8in. Also, the change in temperature profiles through the reactor and possibility of having a stable and uniform combustion zone in a very large diameter reactor will be studied. The change in the amount of heat loss will be studied too since the surface area to volume ratio will change when the reactor diameter is changed while keeping the same height.

\section{REFERENCES}

[1] National Energy Technology Laboratory, Energy Predicament,(2011)

[2] U.S. EIA International Energy Statistics,(2010);http://www.eia.gov/cfapps/i pdbproject/IEDIndex3.cfm

[3] McKendry, P., Energy production from biomass (part 1): Overview of biomass. Bioresource Technology, (2002) 83(1): p. 37-46

[4] World Energy Resources,(2013) Survey: Summaryhttps://www.worldenergy.org/wpc ontent/uploads/2013/10/WEC_Resources_su mmary-final_180314_TT.pdf

[5] Inventory of U.S. Greenhouse Gas Emissions and Sinks: 1990 - 2013 APRIL 15, (2015) U.S. Environmental Protection Agency 
https://www3.epa.gov/climatechange/Downl oads/ghgemissions/US-GHG-Inventory2015-Main-Text.pdf

[6] Renewables 2012 Global status report. World Energy Consumption, 2012); https://en.wikipedia.org/wiki/Renewable_en ergy\#/media/File:Total_World_Energy_Con sumption_by_Source_2010.png.

[7] Gai, C. and Y. Dong, Experimental study on non-woody biomass gasification in a downdraft gasifier. International Journal of Hydrogen Energy, (2012) 37(6): p. 49354944.

[8] Kumar, A., D.D. Jones, and M.A. Hanna, Thermochemical Biomass Gasification: A Review of the Current Status of the Technology. Energies, (2009) 2(3): p. 556581.

[9] Bracmort, K., Is Biopower carbon neutral? Congressional Research Service, (2015)

[10] Rajvanshi, A.K., BIOMASS GASIFICATION. Alternative Energy in Agriculture,(1986) Vol. II: p. 83-102.

[11] FAO, FORESTRY, PAPER 72, Wood gas as Engine fuel, Rome, Italy,(1986) http://www.fao.org/3/a-t0512e.pdf

[12] ASHDEN sustainable solution, better lives,(2016)https://www.ashden.org/biomass -gasification

[13] Dhruv S Deshpande, A.D.P., Shailesh L Patil, Anirudha G Ghadge, V. N. Raibhole*, Testing And Parametric Analysis Of An Updraft Biomass Gasifier. International Journal of ChemTech Research, (2013). Vol.5 (No.2 ): p. 753-760

[14] Sastry, A.B.a.R.C., Biomass Gasification Processes in Downdraft Fixed Bed Reactors: A Review. International Journal of Chemical Engineering and Applications, December (2011). Vol. 2(6).

[15] Patra, T.K. and P.N. Sheth, Biomass gasification models for downdraft gasifier: A state-of-the-art review. Renewable and Sustainable Energy Reviews, (2015). 50: p. 583-593

[16] Muilenburg, M.A., COMPUTATIONAL MODELING OF THE COMBUSTION AND GASIFICATION ZONES IN A DOWNDRAFT GASIFIER, in Mechanical Engineering,(2011). The University of Iowa, Iowa City, Iowa

[17] Bubbling fluidized bed gasification, ANDRITZ international technology group https://www.andritz.com/products-andservices/pf-detail.htm?productid $=14969$

[18] YounesChhiti, M.K., Thermal Conversion of Biomass, Pyrolysis and Gasification: A Review. The International Journal of
Engineering and Science (IJES), (2013). Volume 2(Issue 3): p. 75-85

[19] Yueshi Wu, Q.Z., Weihong Yang and WlodzimierzBlasiak, Two-Dimensional Computational Fluid Dynamics Simulation of Biomass Gasification in a Downdraft Fixed-Bed Gasifier with Highly Preheated Air and Steam. Energy Fuels, (2013)Vol. 27, no 6, 3274-3282 p.

[20] Dejtrakulwong, C. and S. Patumsawad, Four Zones Modeling of the Downdraft Biomass Gasification Process: Effects of Moisture Content and Air to Fuel Ratio. Energy Procedia, (2014). 52: p. 142-149.

[21] Rauch, H.B.a.R., Review Applications of Gases from Biomass Gasification (2006). "Syngas production and utilization" in the Handbook Biomass Gasification. Biomass Technology Group.

[22] Bain, R.L.,USA Biomass Gasification status. IEA Bioenergy Task 33,National Renewable Energy Laboratory, NREL(2012)

[23] British Standard BS: IEC61882:2002 Hazard and operability studies (HAZOP studies) - Application Guide British Standards Institution

[24] Dinesh Mohan, C.U.P., Jr., and Philip H. Steele, Pyrolysis of Wood/Biomass for Biooil: A Critical Review. Energy and Fuels, (2006). 20: p. 848-889 